\title{
Uma introdução ao estudo do Jongo do Vale do Paraíba
}

\author{
An introduction to the study Paraíba Valley's Jongo \\ Penha Aparecida Adriano da Silva Assis ${ }^{1}$, Magno Fonseca Borges ${ }^{2}$.
}

\begin{abstract}
Resumo
Neste trabalho buscamos apresentar algumas reflexões preliminares sobre o Jongo do Vale do Paraíba. Palavras-Chave: Vale do Paraíba. Escravidão. Jongo.
\end{abstract} Como citar esse artigo. Assis PAAS,
Borges MF. Uma introdução ao estudo do Jongo do Vale do Paraíba. Revista Mosaico. 2015 Jan./Jun.; 06 (1): 43-48.

\begin{abstract}
In this work we present some preliminary reflections about Paraíba Vally's Jongo.

Keywords: Paraíba Vally. Slavery. Jongo.
\end{abstract}

Jongueiro novo, pergunte a jongueiro velho Jongueiro novo, pergunte a jongueiro velho Se eu posso botar meu pé Na terra que tem mistério

Jongo Caxambú Renascer de Vassouras

\section{A Escravidão e o Vale do Rio Paraíba do Sul}

O entendimento sobre a escravidão brasileira no século XIX passa obrigatoriamente pela caracterização da produção cafeeira que dominou a economia do país naquele século. Segundo o professor Magno Fonseca Borges, essa produção já vinha sendo feita no Brasil em momento anterior. Mas teve o início de sua consolidação como cultura realizada em grande escala para abastecer o mercado mundial, a partir do início da década de $1820 .{ }^{1}$ A cultura foi desenvolvida com maior fôlego na região conhecida como Vale do Paraíba, no Sudeste. Nosso estudo tem por tema principal a relação entre a escravidão no Vale do Paraíba e a construção de um tipo de manifestação cultural, que em linhas gerais foi identificada como patrimônio imaterial da Nação Brasileira. Trata-se do Jongo do Sudeste. ${ }^{2}$

1 BOGES, M. F. Protagonismo e sociabilidade escrava na implantação e ampliação da cultura cafeeira. Vassouras (1821-1850). Dissertação de Mestrado apresentada ao programa de Mestrado em História da USS, 2005.

2 IPHAN, DOSSIÊ. 5, Jongo no Sudeste. Brasília, DF: Iphan, 2007.
Os pesquisadores Rafael Marquese e Dale Tomich $^{3}$ identificam o final da década de 1820 e o início da década de 1830 como um momento político e econômico importante para a Cultura Cafeeira. Neste momento, a economia brasileira estava enfrentando graves problemas e o café começava a despontar como um dos principais produtos vendidos ao mercado externo. Ao longo da primeira metade da década de 1830 o volume de café negociado ao mercado atlântico ultrapassou o açúcar. Essa condição se manteve ao longo de todo o século XIX e o café passou a ser considerado o esteio fundamental da economia do Império. ${ }^{4}$

É muito importante destacar que àquele momento, estava tendo início um processo de deslegitimação da escravidão negra, em escala mundial. $\mathrm{O}$ processo, encampado pela Inglaterra, em um primeiro momento, forçava o fim do tráfico atlântico de escravos. Mas ao longo da década de 1830 foi transformado em um movimento que buscava o fim do sistema escravista. ${ }^{5}$

Assim, ao longo do século XIX, o sistema escravista foi sendo encerrado em todo o continente americano. Mas, neste processo, Estados Unidos, Cuba e Brasil tiveram seu sistema muito dilatado antes de seu final. O Brasil foi o último país americano a findar a

\footnotetext{
3 MARQUESE, Rafael e TOMICH, Dale. O Vale do Paraíba escravista e a formação do mercado mundial de café. In: GRINBERG, Keila e SALLES, Ricardo (org.). O Brasil Imperial. Vol 2. Rio de Janeiro: Civilização Brasileira, 2009

4 Idem.

5 Idem.
}

1. Graduanda em História pela Universidade Severino Sombra (USS)

2. Doutorando do Programa de Pós-Graduação em História da Universidade Federal do Estado do Rio de Janeiro (PPGH/UNIRIO). Professor nos cursos de Licenciatura em História e Pedagogia da Universidade Severino Sombra. 
escravidão, apenas no final do século, em 1888.

$\mathrm{O}$ que os historiadores têm encontrado como resultados de suas pesquisas, é que até o ano de 1850 , quando o tráfico atlântico foi encerrado, no Brasil, ocorreu uma enorme elevação do número de escravos. ${ }^{6}$ A professora Camilla Agostini, em seu trabalho de mestrado, buscou demonstrar que neste período o maior número de escravos da região foram trazidos principalmente da África Banto centro-ocidental. ${ }^{7}$ Esse é um ponto muito importante. Essas pessoas que foram trazidas a força para a região, a partir de experiências comuns, formaram as comunidades cativas do Vale do Paraíba.

A professora Camilla Agostini realizou pesquisas a partir de dois caminhos. Um primeiro foi realizado através de pesquisas em documentos originais do século XIX. Ela trabalhou com vários tipos de documentos. Pesquisou tanto em inventários, como em processos criminais. Também analisou alguns testamentos e até mesmo alguns livros de atas da Câmara de Vassouras. Mas sua pesquisa teve um outro movimento. Ela buscou estabelecer contato com jongueiros do Vale. Conheceu diversas pessoas e coletou muitas informações sobre à música e a dança. Esse trabalho de história oral permitiu a ela compreender a intima relação entre o jongo, do modo que o conhecemos hoje, e as práticas culturais criadas por escravos em sua vida em comunidade nas grandes fazendas da região. Camilla Agostini iniciou a primeira etapa de seu trabalho com uma poderosa pergunta: Chegam os africanos, e com eles, que África?

Para ela, os etnônimos (que são os nomes de nação apresentados na documentação), devem ser analisados com cautela pelo pesquisador. Isso porque esses nomes de nação, tratado como uma espécie de origem podem remeter a uma origem geográfica, conforme tem sido trabalhado pela grande parte dos estudiosos. ${ }^{8}$ Mas para ela, essa relação não deve ser feita de modo muito direto e mecânico.

Os etnônimos associados aos centro-africanos que chegavam no Brasil (os nomes de nação) sugerem a indicação de um lugar; uma referência de origem ou procedência que podiam representar abstrações europeias bastante genéricas como "Angola" ou "Moçambique", ou serem referências objetivas de um lugar como "Cassange", "Boma" (mercados no interior da África Central), "Monjolo" (área de Monsol, no reino do Tio), "Cabundá" (área de Luanda), ou "Mangangue" (uma variante da palavra que significa "povo do lago"). Pensar nestas representações de particularidades africanas (os etnônimos) como indícios de identidades étnicas entre centro-africanos que acabaram sendo trazidos para o sudeste brasileiro é uma possibilidade que se abre ao

6 SALLES, Ricardo. E o Vale era escravo. Vassouras, século XIX. Senhores e Escravos no coração do Império. Rio de Janeiro: Civilização Brasileira, 2008.

7 AGOSTINI, C. Africanos no cativeiro e a construção de identidades no além-mar. Vale do Paraíba, Século XIX. Dissertação de Mestrado: Universidade Estadul de Campinas, UNICAMP. 2002. P. 10.

8 Este, por exemplo fo mo 8 Este, por exempl foi o modocom: op

A senzalas no Rio de Janeiro, século XIX. São Paulo, Companhia das letras. 2006 pesquisador, sem, contudo, poupa-lo de algumas armadilhas conceituais. A noção de 'origem', 'procedência' ou mesmo 'terra natal' implícita nos nomes de nação deve ser relativizada se pensamos estes etnônimos como possíveis identidades africanas admitidas por escravos no alémmar. (...) Estudiosos da diáspora africana na América (...) têm enfatizado a necessidade de pensarmos a experiência africana no Novo Mundo tendo em vista seu passado e experiência na África, para um melhor entendimento das suas escolhas de ação e interpretação do mundo na diáspora. ${ }^{9}$

Destacamos que o estudo da etnicidade é muito importante. Ele permite compreender como se davam os processos de identificação e diferenciação das pessoas, a partir de parâmetros indentitários, formulados através de referências e memória de experiências vividas no próprio continente africano. Por outro lado, isso ajuda também a compreender os processos de reelaboração dos parâmetros de ressignificação e construção de novas identidades e regimes de sociabilidade escrava que permitissem as pessoas, quando postas em grupo, tecerem parâmetros para a formulação de vivências comunitárias. ${ }^{10}$

Segundo o professor Ricardo Salles, no processo de introdução e ampliação das plantations cafeeira do Vale do Paraíba, a demografia escrava foi muito impactada pela chegada constante de novos escravos, para coabitarem as senzalas. Tratava-se daquilo que ele explicou como um grande caldeirão étnico. ${ }^{11}$ Esse movimento, foi marcado por muitos conflitos dentro das senzalas. Mas foi exatamente em meio a este conjunto bastante conflituoso, que se fez a construção dos códigos comuns que permitiram a escravos ultrapassarem a situação de grupo de pessoas para constituírem alianças, parcerias e valores comuns que garantissem uma vivência em comunidade. As comunidades escravas das zonas de plantations foram forjadas a partir de significações e ressignificações, que, se por um lado, poderia remeter a multiplicidade das experiências africanas, também havia sido criadas e/ou inventadas na vivência comum sob o julgo do cativeiro. ${ }^{12}$

Este processo é semelhante àquele que a Professora Camilla Agostini explicou ao destacar que

Um aspecto muito importante a ser observado (...) é o quanto a travessia do Atlântico e as perspectivas da escravidão serviam como rupturas de modos de ser africanos e o quanto as heranças da "terra natal foram ativadas na formação de identidades no além mar. A atribuição dos nomes de nação aos escravos pode ter sido de certa forma arbitrária nas listagens de traficantes e senhores de escravos. No entanto, os significados a eles conferidos devem ter uma lógica, que podia passar pela incorporação ou rejeição de estereótipos que exaltavam diferenças entre nações criadas pelo tráfico, ou pela observação de

9 AGOSTINI, C. Op. Cit. pag. 15. (Grifo nosso)

10 AGOSTINI, C. Op. Cit. pag. 17. Cf. Magno Fonseca Borges, Op. Cit. capítulo 3 e 4.

11 Salles, R. E o vale era Op. Cit.

12 SALLES, R.; BORGES, Magno Fonseca. (2009) Vassouras - 1830-1850: poder local e rebeldia escrava. In: Carvalho, José Murilo; Neves, Lúcia Maria Bastos Pereira das. (Org.). Repensando o Brasil do Oitocentos. Cidadania, Política e Liberdade. $1^{\circ}$ ed. Rio de Janeiro: Civilização Brasileira, Brasil do Oitocentos. Cid 
naturalistas que tendiam a identificar diferenças linguísticas, contribuindo para a circulação de informações sobre a africanidade dos cativos. Incluindo ainda os significados atribuídos pelos próprios africanos a identidades que poderiam fazer deles iguais a uns e diferentes de outros. ${ }^{13}$

Ainda sobre a questão dos etinônimos, Agostini argumentou que seria possível que houvesse relação entre estes e um dado local, ou origem, mas, que isso nem sempre seria verdadeiro. Um exemplo interessante destacado pela professora reside no caso do depoimento do escravo Lino, em processo criminal em que foi acusado de cometer um crime após uma "brincadeira de Caxambú" em 1872. Ele era conhecido, e também se apresentava como Lino Moçambique. Em seu depoimento, disse se chamar Lino, ser de nação Moçambique e ser natural de Luanda. Outro exemplo que consideramos intressante, foi aquele em que ela recuperou as informações referentes a João, em processo de 1854. Ele se identificava (e também era assim reconhecido por seus parceiros) como João Mineiro. Sua tarefa era a de tratador de bestas de uma tropa. Em seu depoimento declarou que era natural de Luanda. Um ponto a destacar, é que João Mineiro também era chamado por alguns de seus parceiros como "Pai João". ${ }^{14}$

Esses dados, nos permitem acreditar que haveria também um circuito de circulação e difusão de valores culturais, envoltos em toda esta trama de nomeação e identificação das pessoas que viviam sob o julgo do cativeiro. $\mathrm{E}$ isso, certamente tinha alguma referência com as memórias compartilhadas e/ou inventadas, de códigos africanos. Mas, certamente, impactaria a forma de se conhecer e reconhecer as pessoas, vivendo em comunidade no cativeiro.

Vejamos um interessante caso estudado pela professora Camilla Agostini. Ela relatou que no ano de 1836, os escravos Ventura (de nação Cumundá) e Joaquim Moçambique se desentenderam durante $o$ trabalho de roça. Joaquim "ofendeu com palavras seu parceiro Ventura", dizendo-lhe que a gente de nação Cumundá era muito "desavergunhada" e "mandável". ${ }^{15}$ Segundo o depoimento de Joaquim, bem como de outros escravos, o que motivou daquela fala era o fato de Ventura estar trabalhando em ritmo diferente dos demais escravos.

Naquele momento, não havia feitor acompanhando o trabalho. Então Joaquim sentiu-se no direito de retalhar a atitude de Ventura, exigindolhe, mas ação no trabalho. Nesta ocasião, utilizouse de palavras ofensivas. Para tal, utilizou estigmas e chistes aos de nação Cumundá. Ao que parece, Ventura não reagiu bem as ofensas, contra-argumentou e por isso levou uma bordoada na cabeça. Após alguns dias faleceu.

13 AGOSTINI, C. Op. Cit. pag. 19.
14 Idem, pag. 25.

15 Idem, pag. 39-49.
Se por um lado, vemos aqui um tipo de conflito, que em primeiro momento pode ser identificado com desavenças étnicas, este não é o único ingrediente do caso. Joaquim era tido naquela comunidade de senzala como Pai Velho. O desrespeito de Ventura as ordens deste Pai Velho é parte integrante deste conflito.

O proprietário daqueles escravos, Simão da Rocha Loureiro, explicou que "são ordens constantes naquela fazenda que logo que não está presente o que tem o reio segue em poder o mais velho e casado com mais filhos" ${ }^{16}$ É interessante notar que em A paz nas Senzalas, Manolo Florentino e José Roberto Pinto de Goes já ressaltavam a importância dos "cativos mais velhos, os mais curtidos pela escravidão, constituiam um poder que ordenava a vida da comunidade". ${ }^{17}$

O problema não era apenas uma desavença, que poderia ter lugar nas origens africanas. O Pai Velho Joaquim Moçambique, ditava um ritimo de trabalho que não foi respeitado por Ventura, que desafiou a hierarquia de poder estabelecida pelo costume da vida na fazenda. Este enredo ajuda a compreender, como várias das feições das relações construidas nas senzalas do sudeste tiveram origem em um duplo movimento. De um lado, um conjunto de memórias de origem africana, e de outro uma complexa reorganização dos códigos sociais, na vivencia em comunidade das senzalas do sudeste brasileiro.

\section{A Escravidão, o Vale do Rio Paraíba do Sul e o Jongo}

A construção de valores comuns que permitissem aqueles escravos compartilharem experiências, e mesmo, elaborarem/inventarem memórias que lhes permitissem a vida em comunidade, pode ser observado em diversos aspectos da vida cotidiana. Devemos ter atenção a uma importante observação do professor Stanley Stein, sintetizada pela professora Camilla Agostini.

\footnotetext{
Segundo ele, a maioria dos escravos viviam em fazendas populosas. A grande maioria dos escravos precisavam viver e conviver com mais oitenta ou cem cativos. Vejamos que a grande maioria dos cativos, tinham que conviver em senzalas populosas. Tinham que trabalhar juntos. Por isso, era necessário a criação de um conjunto de regras que permitisse a convivência, compartilhassem experiências,e mesmo elaborassem e também inventarem memorias que lhe permitissem a vida em comunidade. A vida dos escravosera regida pelas necessidades da cultura cafeeira, a manutenção da sede e das senzalas, a produção de víveres e o beneficiamento do café. Como a mão-de-obra escrava fosse sempre insuficiente para as necessidades da fazenda, tanto no período do desenvolvimento como no da propriedade ou da decadência, o dia de trabalho do escravo era longo. Começava antes do nascerdo sol prolongando-se, frequentemente, muitas
} 
horas depois do rápido crepúsculo do planalto do Paraíba ${ }^{18}$

Ainda seguindo a narativa de Stein, Agostini nos informa que as cozinheiras se levantavam antes do sol nascer. Eram elas quem acendiam o fogo embaixo dos caldeirões de ferro, de onde saiam os aromas do café; da rapadura e do angu de fubá. Cheiros que anunciavam o amanhecer. Que percorriam as diversas senzalas e, por vezes, se somava ao som do sino tocado pelo capataz para despertar aquelas pessoas que seguiriam para mais um longo dia de trabalho. ${ }^{19}$

Antes mesmo de o sol aparecer no firmamento para iluminar mais um dia, o feitor ou um de seus capatazes negros se encaminhava para um canto do terreiro para tanger o sino de boca larga. As badaladas do sino de ferro fundido; às vezes, o toque de uma buzina ou o rufar de um tambor se espalhava por todo o terreiro. Cheiros e sons marcavam o amanhecer. O terreiro era emoldurado pelos pequenos cubículos, onde dormiam os casais de escravos e nos dormitórios separados, onde se amontoavam os escravos solteiros. Era destas moradias que os cativos saíam, em direção ao terreiro para ficarem em forma e passarem pela contagem do feitor.

Era no terreiro que os cativos eram separados em turmas e recebiam as instruções sobre as atividades a serem desenvolvidas naquele dia. Cada turma tinha o seu próprio feitor. Era ele o responsável por garantir que aquele grupo iria realizar as tarefas diárias. Esse feitor, poderia ter o apoio de um capataz. O ofício do feitor não era dos mais fáceis. Ele deveria supervisionar o andamento do trabalho, manter a ordem e ainda, evitar os conflitos. Muitas vezes o feitor é associado àquele que tinha a função de aplicar os castigos físicos. Isso é verdadeiro. Contudo, esta era a situação que deveria, ao máximo, ser evitada. $\mathrm{O}$ uso da força era uma reserva de poder, que só deveria ser utilizada se necessário. A principal tarefa do feitor era, mediar conflitos e estimular a turma ao alcance de suas metas. Não é à toa, que em várias fazendas, o feitor era também um escravo. Alguém que já teria a experiência de como lidar com o grupo, como manter a sinergia da turma, como garantir que este conjunto de pessoas se tornassem uma equipe de trabalho, e que pudessem viver em comunidade. ${ }^{20}$

Assim sendo, os cativos, saindo de seu sono (de cinco a oito horas diárias) arrastavam-se de suas tarimbas de tábuas cobertas de esteiras. Os trabalhadores da lavoura pegavam as enxadas e as foices penduradas no beiral. No grande tanque, ao lado da senzala, molhavam o rosto e a cabeça, esfregavam os braços, as pernas e os tornozelos. Escravos atrasados apareciam à porta da senzala cantarolando o jongo que satirizava o feitor tocando o sino. ${ }^{21}$ Já faziam uso do canto de trabalho, que

18 AGOSTINI, C. Op. Cit.

20 SALLES, R.; BORGES, Magno Fonseca. Vassouras - 1830-1850: poder local e rebeldia escrava. 20 SALL

21 AGOSTINI, C. Op. Cit. também pode ser encontrado (em sua variante religiosa e de divertimento no Jongo/Caxambú) como forma de comunicação. Tratava-se de uma prática associativa importante na organização social de africanos e afrobrasileiros nos cativeiros do Vale do Paraíba.

Querelas do cotidiano podiam ser resolvidas em desafios de habilidades com a palavra. Era uma forma de aprender, dominar e construir a linguagem própria daquele grupo. Uma linguagem que misturava cheiros, sons e gestos. No campo da língua (idioma), era o momento de se construir falas, que articulavam diversos dialetos africanos e o domínio do português, criando códigos decifráveis a alguns e indecifráveis a outros. Apenas possíveis de serem codificados e decodificados na vivência em comunidade. $\mathrm{Na}$ construção de normas e valores comuns. De visões de mundo comuns. Da criação e recriação de lembranças. De todo um conjunto de coisas que faziam a vida ter sentido.

Durante o trabalho as diversas turmas frequentemente trabalhavam a pequena distância umas das outras e, para imprimir ritmo às enxadas e transmitir comentários sobre o pequeno mundo em que se achavam circunscritos, no qual viviam e trabalhavam suas próprias fraquezas, as do senhor, dos feitores e dos capatazes - o "mestre cantor" de uma turma iniciava o primeiro verso de um jongo. Sua turma repetia em coro o segundo verso, e capinavam todos no mesmo ritmo, enquanto o mestre cantor da turma ao lado tentava responder ao desafio.

\footnotetext{
Um antigo escravo, ainda com fama de hábil cantor de jongo, informava que "o mestre batia no chão com a enxada, os outros escutavam enquanto ele cantava. Depois respondiam." Acrescentava que quando o jongo não ia bem o trabalho não rendia. Os jongos cantados em língua africana se chamavam quinzumba; os cantados em português, mais comuns à medida que desapareciam das turmas os negros velhos nascidos na África, chamavam-se visaria. Parando aqui e ali para dar uma lambada nos indolentes, dois capatazes fiscalizavam as turmas, percorrendo de um lado para outro as carreiras de café e gritando "vamos, vamos"; quando a fiscalização relaxava, os trabalhadores se aproveitavam para diminuir o ritmo do trabalho enquanto escravos e escravas acendiam seus pitos ou se apoiavam à enxada para enxugar o suor. Para racionalizar o desejo de resistência às lambadas e aos gritos do capataz, inventaram a história de que um escravo mais velho e mais vagaroso nunca devia ser ultrapassado em sua carreira de café; do contrário o escravo velho podia arremessar a cinta na carreira de um mais moço, e este seria mordido por uma cobra quando dela se aproximasse. ${ }^{22}$
}

Brincadeira, sátiras, flertes. $\mathrm{O}$ cadenciamento do ritmo de trabalho. Tudo passava pelas diversas formas como se construía uma vivência comum, expressa na linguagem. $\mathrm{O}$ feitor que integrava aquela comunidade, também conhecia estes códigos.

O feitor ou o próprio senhor, vestido de branco e de botas, passeava a cavalo pelo cafezal para fiscalizar o trabalho.

22 AGOSTINI, C. Op. Cit 
Os escravos atentos, fingindo que olhavam para o sol e disfarçando, diziam com afetação, "olha o sol quente vermelho", ou misturavam palavras africanas comuns, do vocabulário dos escravos, com palavras portuguesas como "Ngoma vem aí" para avisar os companheiros que fingiam trabalhar com afinco. Quando o capataz via o fazendeiro aproximar-se, comandava à turma "dêem a bênção", a que os escravos ansiosos por uma pequena folga atendiam, perfilando-se; ou, tirando os chapéus, se benziam, respondendo "vas Cristo." Encerrando a saudação ritual, o senhor também tirava o chapéu, dizia "louvado seja para sempre", e continuava. Imediatamente diminuía o ardor do trabalho. Além de conduzir a cantoria que ritmava o trabalho no campo o jongo também era usado como forma de desafio, podia se manifestar em forma de caçoar de seus senhores, feitores, parceiros, satirizar acontecimentosno cotidiano, ou ainda de saudar e rememorar a ancestralidade. ${ }^{23}$

Por vezes, um feitor até poderia estimular a cantoria no eito, repassando a um mais velho a responsabilidade de construir as falas ritmadas, que seriam acompanhadas pelos demais. Os cantos também podiam ser usados para as reclamações e expressões de insatisfações diversas. Agostini verificou o caso de um cativo, que saiu à porta cantarolando: Aquele diabo dobembo; zombou de mim; nem tempo para abotoar minha camisa; aquele diabo do bembo. ${ }^{24}$

Trata-se, portanto, de espaços da oralidade para a crônica satírica sobre a vida cotidiana, ou mesmo para reverenciar o "passado" com referências a ancestrais ou ao "além-mar". ${ }^{25}$ Espaço de uma linguagem particular e de transmissão de determinado conhecimento, é ainda um espaço de manifestação de um poder firmado pela força " através da palavra". Não sódurante otrabalho no campo, mas especificamente quando se reuniam em torno de tambores, para dançar ao som dos batuques, uma linguagem simbólica e cifrada parece ter sido usada por afro-brasileiros, ainda no tempo do cativeiro. ${ }^{26}$

O caxambú era uma oportunidade de se cultivar o comentário irônico, hábil, frequentemente cínico, acerca da sociedade dentro da qualos escravos constituíam um segmento tão importante. O sistema de polícia e supervisão constante tendiam a abalar o ânimo e a disposição do imigrante africano e de seus filhos; o caxambu com seus ritmos poderosos, com quase completa ausência de supervisão do fazendeiro, com uso das palavras africanas, metáforas para disfarçar as alusões óbvias e os ocasionais tragos de cachaça morna, proporcionavam ao escravos a oportunidade de expressar seus sentimentos em relação aos seus senhores e feitores e comentar acerca das fraquezas de seus companheiros. ${ }^{27}$

Dentro desse contexto, os jongos eram canções de protesto, às vezes, reprimidos. Mas, era também ação de resistência. A forma do jongo, aquele do desafio, expressava bem as reações dos escravos, pois assim como todos os desafios, o objetivo era ocultar o sentido

23 AGOSTINI, C. Op. Cit.

24 AGOSTINI, C. Op. Cit.

24 AGOSTIN, C. Op. Cit.

25 AGOSTIN, C. Op. Cit.

27 AGOSTINI, C. Op. Cit. com as palavras. ${ }^{28}$

\section{A guisa de algumas conclusões preliminares}

Percebemos que os negros que aqui chegaram eram inteligentes e sábios o bastante, para driblarem seus senhores e uma estrutura formada ao redor deles conseguindo comunicar-se através de códigos próprios e específicos criados por eles: o "jongo". Esta compreensão nos ajuda a perceber (de modo contrário ao que algumas visões da época buscavam argumentar ao afirmarem que os negros eram animais e que não pensavam) que o jongo representava uma importante estratégia de visão comunitária.

Não podemos dizer que o jongo seja africano, como alguns historiadores escrevem. Afirmamos que não é! O Jongo está relacionado diretamente a uma forma de sociabilidade escrava, muito específica, desenvolvida nas plantations cafeeiras. Por isso, foi identificado pelo IPHAN como jongo do Sudeste. Essa forma de expressão é muito regionalizada, não sendo verificada em outras porções do Brasil, manifestações com os mesmos traços.

Quando passaram a viver no Vale do Paraíba, e conviver em senzalas muito populosas e com ritmo e forma de trabalho muito específica, o Jongo foi construído, paulatinamente, como uma ferramenta de sociabilização. Os escravos do Sudeste tiveram que reinventar suas práticas, suas músicas e suas culturas adequando-se convenientemente ao ambiente em que foram forçados a viverem. Por meio de suas estratégias de sociabilidade, resistiram aos rigores do cativeiro. Implementaram profundas e complexas negociações que lhes ampliou possibilidades de melhor qualidade de vida e conquista de direitos. Os cantos estiveram na base de muitas destas lutas. E o Jongo foi uma das grandes conquistas.

Para Maria de Lourdes Ribeiro ${ }^{29}$ os escravos usavam uma linguagem simbólica que lhe servia como meio de comunicação "completamente indecifrável. Além disso é do nosso conhecimento que os escravos conheciam o calendário anual das festas e dias santos, especialmente porque estes eram os dias livres".

\section{Referências}

AGOSTINI, C. Africanos no cativeiro e a construção de identidades no alémmar. Vale do Paraíba, século XIX. Dissertação de Mestrado: Universidade Estadual de Campinas, UNICAMP. 2002.

BOGES, M. F. Protagonismo e sociabilidade escrava na implantação e ampliação da cultura cafeeira. Vassouras (1821-1850). Dissertação de Mestrado apresentada ao programa de Mestrado em História da USS, 2005.

28 STEIN, Stanley. Vassouras: um município brasileiro do café (1850-1900). Rio de Janeiro: Nova Fronteira. 1990. P.246 
FLORENTINO, M. Góes, J.R., A paz das senzalas: famílias escravas e tráfico atlântico, Rio de Janeiro - 1790-1850. Rio de Janeiro: Civilização Brasileira, 1997. Reis, João Jose, Rebelião escrava no Brasil: a história do levante dos males, 1835. São Paulo: Brasiliense, 1985

GOMES, Flavio dos Santos. HISTÓRIAS DE QUILOMBOLAS -

Mocambos e comunidades de senzalas no Rio de Janeiro, século XIX. São

Paulo, Companhia das letras. 2006

IPHAN, DOSSIÊ. 5, Jongo no Sudeste. Brasília, DF: Iphan, 2007.

MARQUESE, Rafael e TOMICH, Dale. O Vale do Paraíba escravista e a formação do mercado mundial de café. In: GRINBERG, Keila e SALLES, Ricardo (org.). O Brasil Imperial. Vol 2. Rio de Janeiro: Civilização Brasileira, 2009

RIBEIRO, Maria de Lourdes Borges. O jongo. Cadernos de Folclore, $n^{\circ} 34$, Rio de Janeiro, FUNARTE, 1984

SALLES, Ricardo. E o Vale era escravo. Vassouras, século XIX. Senhores e Escravos no coração do Império. Rio de Janeiro: Civilização Brasileira, 2008.

SALLES, R.; BORGES, Magno Fonseca. (2009) Vassouras - 1830-1850: poder local e rebeldia escrava. In: Carvalho, José Murilo; Neves, Lúcia Maria Bastos Pereira das. (Org.). Repensando o Brasil do Oitocentos. Cidadania, Política e Liberdade. $1^{\circ}$ ed. Rio de Janeiro: Civilização Brasileira, 2009, v. 1, p. 437-460. 